\title{
Metodología y recursos didácticos para el curso de Ética Profesional
}

L

as materias de Filosofía que se ofrecen en las diversas carreras profesionales suelen ser vistas como cursos difíciles o bien como materias de "relleno", pero lo que no se puede negar es que son un espacio para reflexionar en torno a temas que, como seres humanos, nos preocupan por su injerencia en nuestra vida.

En el caso concreto de los cursos de Ética Profesional, se busca que los futuros profesionistas reflexionen acerca de las implicaciones que su actividad profesional conlleva en la sociedad y la naturaleza; para ello, es necesario buscar la metodología y los recursos didácticos que mejor ayuden a alcanzar este objetivo.

El curso se acompaña con un fundamento teórico para acercar a los estudiantes a los conceptos importantes en torno a la ética, la moral y los valores. Dicho esfuerzo se complementa con métodos y técnicas didácticas que impliquen una participación activa por parte de los estudiantes, lo que no sólo lleva "al educando a observar, criticar, investigar, juzgar, sacar conclusiones, correlacionar, diferenciar, sintetizar, conceptualizar y reflexionar" (Nérici, 1990: 37), sino también contribuye a que perciban la materia y sus contenidos como algo más cercano tanto a su vida personal como a su futura práctica profesional.

La metodología que se va a utilizar dentro del curso es el constructivismo, que pretende que los estudiantes vayan incorporando también aquellas experiencias e informaciones obtenidas fuera de la escuela, y que puedan llegar a complementar los contenidos escolares.

En cuanto a los recursos didácticos, se utilizan películas (por ejemplo "El informante", "Erin Brockovich", entre otras), lecturas diversas -incluyendo cuentos como "Carta a un zapatero que compuso mal unos zapatos"-, cuestionarios, exposiciones por parte de los estudiantes, análisis de noticias, análisis del código ético de la profesión, entre otras.

Para lo anterior, se toman en cuenta algunos de los principios didácticos mencionados por Imídeo Nérici en su obra Metodología de la enseñanza (1990: 54-56), de los cuales se destacan los siguientes:

- Principio de la participación: implica llevar al estudiante a una actitud activa frente a las diversas tareas propuestas en el curso, ya que un estudiante pasivo tiende a ser conformista, y a aceptar lo dicho por el profesor generalmente sin cuestionarlo. 
- Principio de la espontaneidad: sugiere la invitación a los estudiantes para que expresen ideas, opiniones y hasta emociones de lo que se va tratando en el programa, lo cual, además de formar parte del principio anterior, implica reflexión de sí respecto a los temas de clase y, por ende, conlleva a una toma de conciencia y responsabilidad respecto a su formación académica.

- Principio de vivencia: en la medida que los contenidos lo permitan, significa que el alumno haga uso de sus experiencias para darle sentido a lo que se está estudiando; sin embargo, dice Nérici (1990: 55) que "cuando ese contacto directo no es posible, deben utilizarse los recursos audiovisuales"; de hecho actualmente el uso de este tipo de medios didácticos es recurrente y de gran ayuda para facilitar conceptos abstractos.

- Principio de transferencia: este principio busca que los estudiantes sean capaces de aplicar los conocimientos en diversas y nuevas situaciones, tanto personales como profesionales.

- Principio de reflexión: "pone énfasis en la preocupación fundamental de la enseñanza $[. .$.$] hacer que el educando razone, reflexione" (Nérici,$ 1990: 56), pero no sólo en los contenidos de la materia o en su área de formación, sino que lleve esa reflexión a diversos ámbitos de la vida y socialización.

- Principio de responsabilidad: "el principio [...] de la reflexión sólo tiene valor si esa reflexión contribuye a madurar el sentido de responsabilidad del ser humano" (Nérici, 1990: 56). La responsabilidad es una característica que implica maduración, la capacidad de responder por las decisiones, acciones y omisiones, de ahí que sea de suma importancia que a través de la formación académica se trabaje para ayudar a desarrollarla.

Por ejemplo, en el curso de Ética Profesional que se imparte en la licenciatura en Mercadotecnia, se les encarga por equipos un proyecto de marketing (ya sea marketing verde o marketing social) para alguno de los siguientes temas:

- Salud: tabaquismo, nutrición.

- Medio ambiente: contaminación, uso de recursos.

- Educación: alfabetización, acoso escolar.

- Algún otro elegido por los estudiantes.

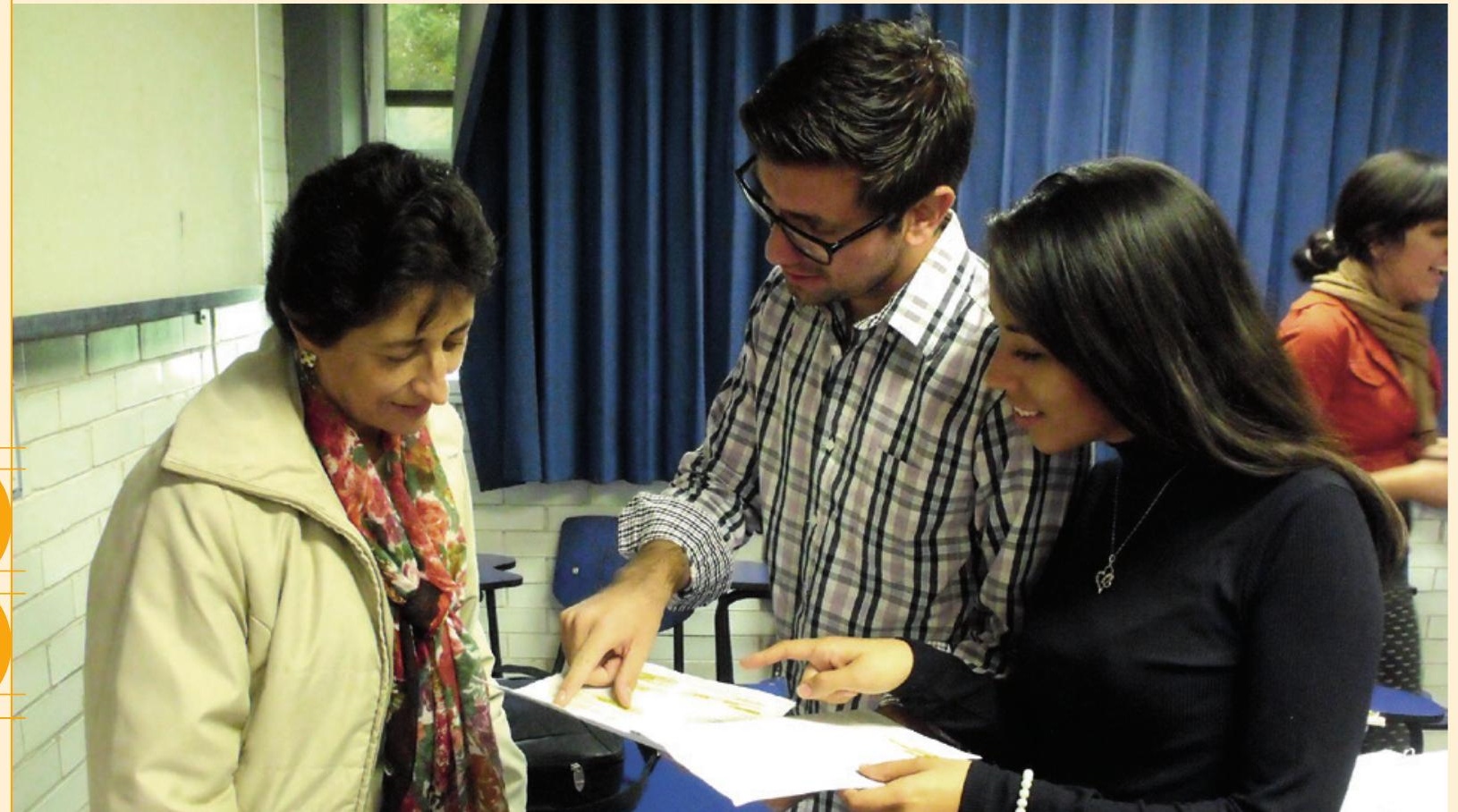


El objetivo es que los educandos hagan un análisis del problema elegido y propongan una solución desde su área de formación profesional, con lo cual se busca que relacionen los contenidos del curso con lo visto en otras materias, para así lograr su transversalidad.

Asimismo, con esta actividad se cumple con los siguientes aspectos de lo propuesto en el Modelo Educativo Institucional (MEI) (UAA, 2007: 9), en lo que a los estudiantes se refiere:

- "Son capaces de desarrollar los valores de la cultura humanista, lo que les permite entender el mundo que les ha tocado vivir e influir positivamente en éste" (UAA, 2007: 9): al buscar atender una problemática actual están tomando conciencia de la misma, y al proponer una solución están ofreciendo la puesta en práctica de valores sociales, vitales, entre otros, con los que buscan cambiar la manera como hasta ese momento se ha vivido dicha situación.

- "Son constructores de su propio conocimiento al seleccionar, elaborar, organizar, utilizar y dar significado a la información para actuar en su entorno, a través de las variadas tareas que han sido diseñadas para ellos" (p. 9): al aplicar a una situación real los conocimientos obtenidos muestran capacidad de análisis y selección de los contenidos más adecuados para su propuesta, lo cual resulta favorable para analizar su actualidad e importancia.

- "Muestran actitudes favorables hacia el trabajo colaborativo" (p. 9): al trabajar en equipo tienen que aprender valores como la tolerancia, la objetividad, ser críticos, entre otros, lo cual, sin duda alguna, es favorecedor para tener un buen desempeño profesional.

\section{Reflexiones finales}

Es importante localizar, adaptar o crear los recursos didácticos adecuados para que el futuro profesionista, de acuerdo con su perfil, visualice la aplicación de los contenidos temáticos abarcados en su contexto profesional.

En la medida de las posibilidades, hay que buscar integrar contenidos de otros cursos para que se alcance la transversalidad, y con ello ayudar a los estudiantes para que se den cuenta que los conocimientos de las diversas materias pueden fusionarse y formar parte de un todo: su profesión.

Se debe trabajar en generar aprendizajes significativos a través de actividades que lleven a los estudiantes a aplicar los conocimientos a situaciones reales, lo que reflejará compromiso por parte del docente respecto a su contribución para la formación de profesionales; y a los educandos les permitirá desarrollar diversas habilidades que les serán de utilidad en su ejercicio profesional.

\section{Fuentes de consulta}

Nérici, I. (1990). Metodología de la enseñanza (4ª Edición. $1^{\text {a }}$ Reimpresión). México: Editorial Kapelusz Mexicana.

UAA. (2007). Modelo Educativo Institucional. Correo Universitario, Sexta época, Núm. 16. Recuperado el 19 de junio de 2014 en: http://www.uaa.mx/nu/. 